\title{
Attachment State of Mind and Trauma in Mother and Baby Home Adoptees
}

Natasha Dalton $^{1 *}$, Marian McLaughlin $^{2}$, and Tony Cassidy ${ }^{3}$

${ }^{1 *, 2,3}$ School of Psychology, Ulster University, Coleraine, United Kingdom

*Corresponding author: Natasha Dalton, Dalton-n1@ulster.ac.uk, School of Psychology, Ulster University, Coleraine, BT52 1SA, Northern Ireland

\section{Keywords:}

Adult Attachment Interview, AAI, State of mind, Attachment, Attachment theory, trauma, mother and baby homes, adoptees, adoption, survivors, attachment trauma, adoption trauma.

\section{Data availability statement:}

The data that support the findings of this study are available on request from the corresponding author. The data are not publicly available due to privacy or ethical restrictions.

\section{Acknowledgements:}

We would like to thank our participants for making this research possible.

\section{Funding:}

The authors received no financial support for the research, authorship, and/or publication of this article.

\section{Declaration of Conflicting Interest:}

Authors state that there is no conflicting interest. 


\begin{abstract}
Objectives. This study two had two aims: to establish participant's state of mind (SOM) with regards to attachment using the Adult Attachment Interview (AAI) (George, Main, and Kaplan,1985-1996) and to explore the experiences and impact of adoption amongst adults adopted from mother and baby homes in the UK and Ireland.
\end{abstract}

Methods. The current study made use of all information gained by the AAI by analysing the interview transcripts in two ways: (i) by using the AAI scoring system (Main, Goldwyn and Hesse, 2003) to assess each participant's SOM (ii) thematic analysis of the transcripts producing an inductive set of themes.

Results. All participants had an insecure SOM with regards to attachment. Four out of the five participants were unresolved/disorganised, and preoccupied was the most prevalent underlying three-way classification. Qualitative analysis of transcripts identified four overarching themes: (i) Identity and Belonging; (ii) Trauma; (iii) 'Silenced' Coping and (iv) Adverse Parenting which reflected their experiences of adoption.

Conclusion. Findings indicate that participants may be more susceptible to trauma associated with loss. Findings highlight the importance of suitable adoption placements and vetting of potential adopters. These results have clinical and research implications and add to the broader discussion of trauma related to adoption. 


\section{Introduction}

Mother and baby homes were institutions developed to provide accommodation for unmarried mothers and their children. Many of these homes gained notoriety because of maltreatment that occurred within them. The McCormick et al., (2021) report on mother and baby homes in Northern Ireland was based on an extensive trolling of records and oral histories collected from women, staff, social services and the children who experienced them. The report states that "in the vast majority of cases, trauma and, often, mental health issues have been an outcome of birth mothers'experiences around their pregnancy" (McCormick et al., 2021. p. 21). The survivors reported that these were more prevalent where adoption was the outcome, and that these institutions created barriers to accessing their birth records. Available records suggest that $26 \%$ of children were left with their mothers, $32 \%$ went into institutional care, $23 \%$ were adopted, and $15 \%$ went into foster care.

Adoption research offers a unique insight into the nature of attachment relationships. Many adoptees and care-experienced individuals are faced with attachment disruption and the task of forming attachments to new caregivers. The length of time spent in care, the quality of care or type of care background and adoption pre-history can vary significantly from one individual to the next. Infants placed for adoption may be more likely to have experienced prenatal or birth complications and have had parents with higher levels of psychopathology than the general population (Edens and Cavell, 1999). However, mother and baby homes were atypical from an adoption and fostering perspective. Unlike the removal of children from high-risk homes and maltreatment, this practice was unnecessary; these children had caregivers. Previous research considering risk factors attributed to birth parents' lifestyle, addiction or abuse in the preadoption period may not apply to mother and baby home survivors. Women were committed to 
the homes, and children were removed from their care only because they did not conform to what was deemed socially acceptable by religious orders at the time.

Mother and baby homes were also unique from an attachment point of view because some children could spend their early lives with their mothers, albeit within an institutionalised setting. Meta-analytical findings have shown that institutionalised care is a risk factor for disorganised and insecure attachment classifications (van den Dries et al., 2009; Lionetti et al., 2015) and attachment disorders (Kennedy et al., 2017). Adoption itself also appears to be a risk factor for insecure attachment and disorganised classifications (van Ijzendoorn and Juffer, 2006).

Knowledge of attachment classification is important because attachment security can profoundly impact an individual's life course. Clinical findings have found a strong association between psychiatric diagnoses and attachment insecurity (van Ijzendoorn and Bakermans-Kranenburg, 2008). Attachment security, on the other hand, is a protective factor against mental ill-health (McMahon et al., 2006; Bakermans-Kranenburg and van Ijzendoorn, 2009; Fearon et al., 2010) and physical ill-health (Dagan et al., 2018; Ehrlich, 2019; Ehrlich et al., 2019). There also appears to be a transgenerational risk of parental insecurity, as adult attachment classification measured by the Adult Attachment Interview can predict infant attachment pattern (van Ijzendoorn, 1995).

The Berkeley Adult Attachment Interview (AAI) (George et al., 1985) remains the gold standard measure of adult attachment. The AAI is a one hour long semi-structured, semi-clinical interview consisting of 20 questions that focuses on the interviewee's early and present-day attachment relationships and experiences and the effects these experiences have on current functioning (Main, 1991). The AAI places two demands on the speaker; to recall and reflect on their attachment life histories whilst simultaneously maintaining a coherent and collaborative 
discourse. The analysis of transcripts of the AAI centres not only on the speaker's ability to recall events from their childhood, but also on the coherence and plausibility of the narrative. The result of the AAI analysis allocates the speaker a classification for their overall state of mind (SOM) with respect to attachment (Main, 1985). The SOM is said to provide "....rules and rule systems for the direction of behaviour, the felt appraisal of experience, and the direction and organisation of attention and memory" (van IJzendoorn, 1992, p. 80). There are five main classifications which the speaker can be assigned: secure-autonomous; insecure-dismissing; insecure-pre-occupied; unresolved with respect to loss or trauma and cannot classify. There are also 12 further sub-classifications. An extensive research base has shown that the individual differences in the narratives produced during the AAI significantly correlate with infant's responses during a behaviour-based assessment of separation and reunion, known as the Strange Situation Procedure (SSP) (Ainsworth et al., 1978; van IJzendoorn, 1995). This well-established relationship between parental AAI classification and infant SSP attachment pattern has been found in foster parents with their fostered children (Dozier et al., 2001). It has even been shown to predict infant attachment pattern before the first child is born (Fonagy et al., 1991).

Despite numerous reports and commentaries, there appears to be no empirical research on the impact of adoption from mother and baby homes. As it is known that over 10,500 women were admitted to mother and baby homes in Northern Ireland alone (McCormick et al., 2021), it is unimaginable how many lives across the UK and Ireland have been impacted by this practice. This study aims to shed light on the attachment and experiences of the now-adult children adopted from this source, and to inform future research and clinical practice. 


\section{Methods}

\section{Participants}

Participants were recruited as part of a broader study of attachment in older $(30+)$ adopted and care-experienced adults. Five of the participants recruited were born in mother and baby homes in Ireland and the UK. These five participants were then grouped and analysed separately for the current study. Participants were recruited via social media posts on Twitter and Facebook.

Procedure

Due to the ongoing Covid-19 pandemic, a decision was made for both researcher and participant safety that interviews should take place via an online format. Although only audio was recorded, video was used by both parties throughout to recreate an in-person interview. Both participant and researcher undertook interviews in a quiet and private area of their homes away from other individuals. The interviews were transcribed verbatim in accordance with the guidelines outlined and detailed in the AAI manual supplementary material (Main, Goldwyn and Hesse, 2003).

\section{Measure}

The AAI (George, Kaplan and Main, 1996) was used to determine participant SOM with regards to attachment. The AAI typically takes at least an hour to administer, and all the interviews lasted on average one hour, 11 minutes. The system rates inferred parental behaviour across five different scales, followed by scoring from 12 state of mind scales and finally determining the participants classification with the use of the classification system section of the manual. There are three main organised states of mind, secure-autonomous $(\mathrm{F})$, insecuredismissing (Ds) and insecure-preoccupied (E); and two further classifications, 
unresolved/disorganised (U/d) and cannot classify (CC) and 12 sub-classifications. The speaker is considered secure if they appear to be valuing of attachment, if they are objective of relationships and experiences and seem to flexibility switch between the two demands of the interview. A secure narrative is coherent and collaborative. Both types of insecure classifications have marked incoherences in their discourse. Dismissing speakers dismiss or minimise attachment relationships and their impacts; they defend against conscious awareness of attachment difficulties, they may idealise or degrade relationships. Preoccupied speakers do the opposite they give sustained and obsessive attention to attachment relationships and experiences and maximise their effects. Preoccupied speakers express this either through anger or, more rarely, with passivity or fear. In addition to these three organised strategies, speakers who show lapses in monitoring of reasoning or discourse during discussion of loss or trauma are placed into the unresolved category. Lastly, transcripts are assigned cannot classify if they cannot be placed into any of the previous categories.

\section{Data Analysis}

The current study made use of all information gained by the AAI by analysing the interviews in two ways: (i) by using the AAI scoring system to reveal each participant's SOM (ii) analysing the transcripts qualitatively to produce an inductive set of themes.

An inductive approach was taken to the qualitative analysis due to the lack of data on this population. Thematic analysis (TA) was guided by Braun and Clarke's six-step framework, (2006) and managed by NVivo 12. Transcripts were line-by-line coded and initial codes were then sorted into categories, once an initial thematic framework was created, data sets were reassessed with potential themes in mind for further references of each theme. Each theme was reviewed in correlation to references from the transcripts and the data set as a whole. TA was 
conducted by two researchers who independently analysed the transcripts and then met to agree on the present themes. Decisions regarding refinement of themes and sub-themes were recorded throughout the entire process in NVivo 12.

\section{Ethical considerations}

The study was reviewed and approved by the School of Psychology Ethics Committee. The researcher undertook training in administering and using the AAI prior to the study. The interviews were carried out through virtual media and the researcher was in close contact with supervisors at all times. Participants were fully informed and provided written consent to participate. Information on support services was provided to participants.

\section{Results}

The results of this study are presented here in two sections: (i) AAI classifications (table 1) and (ii) thematic framework and themes. All participants were classified as having an insecure SOM by the AAI scoring system (table 1). Most participants were unresolved and preoccupied was the most prevalent organised classification. When participants are rated as unresolved, the coder must choose a best-fitting alternative organised classification. In the case of participants 1-4, this underlying classification was insecure-preoccupied. The preoccupied classification takes three forms: angrily preoccupied (most common), passively preoccupied and fearfully preoccupied. Two participants had the E2 subclassification, which is angrily preoccupied. During E2 interviews, the speaker goes beyond what is asked in the question and overwhelms the interview with grievances of one or both parents. Participants 1 and 2 exhibited rarer forms of the preoccupied classification, falling into the sub-classification E1 "passively preoccupied" and E3 "fearfully preoccupied". The former subclassification E1 is found approximately in two out of 120 low-risk transcripts and, interestingly is also uncommon in clinical and violent populations 
(Main, Goldwyn and Hesse, 2003). Finally, participant 5's transcript was classified as insecuredismissing and placed into the Ds1 sub-classification, making participant 5 the only participant to have an organised yet insecure primary classification. In Ds1 transcripts, the speaker appears to dismiss most attachment-related thoughts and seems unaware of the effects of early experiences. Two out of the four unresolved/disorganised participants had suffered abuse from their parents. Most participants were older than 55 years old and mainly male. 
Tables

Table 1

Participant AAI classifications

\begin{tabular}{lllll}
\hline Participant & Sex & Age & Primary classification & Sub- \\
& & & & classification \\
\hline Participant 1 & M & 55 & Unresolved/disorganised & U/E3 \\
Participant 2 & F & 59 & Unresolved/disorganised & U/E1 \\
Participant 3 & M & 56 & Unresolved/disorganised & U/E2 \\
Participant 4 & F & 66 & Unresolved/disorganised & U/E2 \\
Participant 5 & M & 63 & Dismissing & Ds1 \\
\hline
\end{tabular}


Table 2

Thematic framework

\begin{tabular}{|c|c|}
\hline Superordinate themes & Sub-themes \\
\hline \multirow[t]{3}{*}{ Belonging and Identity } & - Never fitting in \\
\hline & - Being flawed \\
\hline & - Disposable \\
\hline \multirow[t]{3}{*}{ Trauma } & - Abuse \\
\hline & - Understanding trauma/reflecting on trauma \\
\hline & - Recovery/Post traumatic growth \\
\hline \multirow[t]{2}{*}{ 'Silenced' Coping } & - Self-reliance \\
\hline & - Suppressed emotions \\
\hline \multirow[t]{4}{*}{ Adverse parenting } & - Harsh parenting \\
\hline & - Parental apathy \\
\hline & - Balanced view of parenting \\
\hline & - Lasting impact on relationships \\
\hline
\end{tabular}


Data clustered around four superordinate themes: 1) Belonging and identity, 2) Trauma, 3) 'Silenced' Coping and 4) Adverse parenting. Although the impact of adoption was not directly questioned, all participants had spoken of the effect their adoptive experiences had on their attachment relationships.

\section{Belonging and Identity}

The first theme captures how participants' adoptive status impacted how they saw themselves, and how they viewed their relationships with others. All participants stated that they never felt like they fitted in with family and or peers. Some had expressed a marked difference between themselves and other family members, either in childhood or recently in adulthood, participant 1 stated:

"But the way I processed it is, I'm not the same as everybody else, that I'm very different. So you have Jamie is a member of the family, Sarah is a member of the family, Jill is a member of the family, but there is something a little bit unusual about me. I'm not a member of this family."

Every participant spoke of feeling flawed or not good enough:

"But you always, always live with the idea that [you're] never, never good enough-- no matter what you do, what success you have, there's always a little bit that holds back" 
Participant 2 highlighted how this feeling may be related to being an adoptee:

"Um, but--I I felt flawed, and I don't know and and that might be a common thing for adoptees anyway"

Participants spoke of feeling disposable in romantic relationships or recounted memories of adoptive parents threatening to "send them back" or disowning them. Those who had not reported memories of direct threats of abandonment mentioned that it still felt as though this might happen or spoke of fears of being "sent away again".

“...though I do remember my mother being very angry once and and seemed to be telling me she was going to send me back."

\section{Trauma}

A prominent theme identified from the data was trauma. Four out of the five participants spoke of trauma they had experienced and the process of coming to terms with this. The same participants also spoke of their recovery processes. It is of note that the only participant who did not mention trauma, participant 5, had an insecure-dismissing SOM.

Most participants had experienced physical, emotional, or sexual abuse, either at the hands of their adoptive parents, and or others. In the following extract, the participant touched on the physical abuse committed by his adoptive father: 
"Er, and then when he when I got up to kind of 13, 14, h-he used the closed fist quite a bit as well. So quite violent”

Participant 4 spoke of sexual abuse by an unknown perpetrator.

“...unfortunately I was sexually abused as a child.”

Every participant who spoke of trauma also talked about the lengths they had gone to understand or reflect on their trauma. Participants seemed aware of the impact trauma may have on current functioning:

"I've got quite a strong startle reflex, and, um, I'm always, I can how that's carried into adulthood is if I'm with a partner, I might say, are you all right? And like my partner says, stop, asking if I'm all right, but really, I know that's a hangover from childhood going, are you all right, Mummy?"

The final sub-theme within this superordinate theme, recovery, encapsulates the descriptions of participants' recovery processes. All spoke of attending therapy either in the past or are still regularly attending therapy. 
"I had therapy and I'd become clearer thinking, you know, you sort of start to realise that actually my reaction to something is completely-- not right. So why am I doing that?"

Participant 1 talked about pouring the pain of his adoption experience into his artwork, which helps to aid his recovery as well as helping others within the adoptive community.

"I am able to contribute to the adopted community in a very rich, and a very meaningful way. And I don't think I would be able to unless I had the experiences I've had."

\section{3. 'Silenced' Coping}

When asked about childhood, all participants indicated that they did not feel like they could approach their adoptive parents in times of hurt or distress, and as a result, had learned to cope with hurt by themselves. This theme was created to capture references to lack of needing and suppression of help seeking behaviours described by participants. Every participant recounted self-reliance when hurt or upset in childhood. The following quote from Participant 3 was answered in response to the question "what did you do when you were upset as a child?"

"Erm, I I generally, just got on with it and shut up"

Similarly, in the following example, participant 4 recalls handling physical hurt independently: 
"I'd come off of a swing though really badly and walked myself home."

As a consequence of feeling like they could not turn to their parents in childhood to alleviate distress, participants spoke of learning to cope by suppressing and internalising their emotions when upset:

"I probably would have an internal tantrum. and get over it and then try to figure out how to how to deal with the situation".

One participant describes regulating her behaviours to hide upset:

"things you let show and you'd internalise them. -even a small, you know, as a sort of, probably a 10-year-old, you could face and, you know, just make it look as though you were fine."

\section{Adverse parenting}

The final theme identified from the data was adverse parenting. Four out of the five participants had reported harsh parenting through severe disciplinary actions or emotional maltreatment, which left a lasting impression on the participant. Participant 1 recounts how his adoptive father would physically punish him for wrongly repeating the alphabet: 
"Ahm, and I'm dyslexic and I have a memory of me repeating the alphabet and every time I got it wrong, he would hit me with a wooden spoon."

In the below quote, the participant describes his adoptive father forcing him and his siblings to go to work with him in childhood.

"Which was torturous for us as children, because as soon as we were, kind of big enough to be able to go working with him, he dragged us to go out working with him, hail rain or fucking shine."

Participant 5 did not mention harsh parenting of any kind. Descriptions of parental behaviour in childhood revealed parental apathy, either through examples of disinterest in achievements or activities or belittling childhood interests. For example one participant spoke of receiving the lead role in a play and that her parents did not turn up to watch. In the later quote she states that she would have been surprised if they had:

"But, ahm, you know where you stand when your parents don't turn up." "I probably wasn't expecting them to turn up-- I'd probably be shocked if they had."

Despite accounts of harsh parenting and parental apathy, all participants considered their parents' points of view and would explain their possible motivations or place parenting styles within the context of the era. 
“...she was a single mum with four kids, ahm, it was very, very stressful. She had to learn how to drive a car, she had to learn how to get a job. Ahm, and she was stressed and she took it out on us, and took it out on me."

Every participant expressed how the experiences with their adoptive or birth parents impacted their current relationships. One participant described how his birth mother visiting and then leaving had caused him to have an ambivalent view of relationships today.

"[Birth mum came] to visit and I used to love seeing her, but then she would go and I'd be very upset. So I then started to associate her coming with the upset of her leaving. So, it was extremely confusing, and I ended up ah, having a very mixed relationship with [birth mum] arriving in the first place, at least that's my theory. And, in, when I look back on my my adolescence, and my adult life, I can I can imagine or I can see this pattern of me, sort of wanting a relationship, but also sort of wanting to hold back at the same time."

Participant 5, who spoke of having had a good relationship with his adoptive parents theorised that not witnessing them argue or address potential problems may have affected his conflict resolution skills. However, participants who spoke of harsh parenting or abuse by their adoptive parent(s) touched on how this has had a detrimental and lasting effect on relationships since: 
'I think there's always a sense I don't want to rely on any one person. I don't want to, I don't want to commit to that person because I don't want to give everything to that person, because what happens if they go?" 


\section{Discussion}

The current study aimed to reveal each participant's SOM with regards to attachment and to explore the experiences and impact of adoption amongst adults adopted from mother and baby homes. The aims were achieved using the AAI, which was analysed in two ways: (i) by using the AAI scoring system (Main, Goldwyn and Hesse, 2003) to uncover each participant's SOM (ii) thematic analysis of the transcripts, which produced an inductive set of themes. The AAI analysis determined that all participants had an insecure SOM, and the majority were unresolved. The most prevalent three-way organised classification was preoccupied. Participants 1 and 2 had rarer preoccupied sub-classifications, E1 and E3; the first is found in approximately two out of 120 low-risk samples and does not have a higher prevalence in clinical or violent populations (Main, Goldwyn and Hesse, 2003). Qualitative analysis of the transcripts produced four themes: participants spoke of issues regarding belonging and identity; trauma was a prominent theme in participants' discourse; participants spoke of adverse parenting from their adoptive parents. As a result of experiencing adverse parenting in childhood, participants appeared to internalise emotions and coped with distress by themselves, references to this became a theme known as 'silenced' coping.

The findings are consistent with previous research, which found institutionalised settings and adoption to be a risk factor for disorganised and insecure attachment classifications (van IJzendoorn and Juffer, 2006; van den Dries et al.,2009; Lionetti et al., 2015). A meta-analysis of more than 4,200 AAI classifications conducted by van IJzendoorn and Bakermans-Kranenburg, (2008) revealed that both types of insecure SOM are overrepresented in clinical populations. Specifically, individuals with borderline personality disorder and those who have experienced abuse or suicidal ideation more often have an insecure-preoccupied classification. Unresolved 
classifications are also strongly correlated with borderline personality disorder, abuse, and suicide and are overrepresented in clinical populations. The unresolved classification remains crucial in understanding patients with various clinical diagnoses. Our AAI analysis agrees with these findings; most participants had experienced abuse in childhood and had primary classifications of unresolved and forced three-way organised classifications of preoccupied.

The four participants who had an unresolved classification had higher $\mathrm{U}$ scores regarding loss, i.e. exhibited signs of disorientation and disorganisation during discussions of loss more so than trauma. Benjamin et al., (2019) postulated that loss of a loved one could be exacerbated in adoptees due to the past loss of birth parents. Goldwyn and Hugh-Jones (2011) reported that the experience of a permanent and sometimes sudden loss of one or both birth parents through fostering or adoption is in itself traumatic. Goldwyn and Hugh-Jones (2011) found evidence for disorientated speech, namely failure to name, during separation discussions. Whilst participants in the current study did not exhibit disorientated speech when referencing the separation from their birth parents or adoption, there were eight references to separation from birth parent(s) through adoption as being perceived as a loss. Participants in the Goldwyn and Hugh-Jones (2011) were adolescents aged 14-17 years old. It is possible that over time and through experience, participants learned to resolve verbal incoherences in discourse regarding separation from birth parents.

The McCormack et al. (2021) and the Final Report of the Commission of Investigation into Mother and Baby Homes (2021) both show that the experiences of women who were committed to mother and baby homes were traumatic. The present study supports this finding in mother and baby home adoptees as trauma was a prominent theme alongside unresolved SOM in almost all participants. Research has shown a significant relationship between parental 
unresolved AAI classification and infant disorganised attachment pattern (van IJzendoorn, 1995). Main and Hesse (1990) theorised that the exact mechanism which gives rise to lapses in the monitoring of reasoning or discourse during discussions of loss or trauma could also bring about frightening and frightened parental behaviour during interactions with their children. It is likely therefore, that mother and baby home adoptees were already at risk for transgenerational trauma. This, combined with early life spent in institutionalised care, permanent separation from birth parents, and abuse and harsh parenting from adoptive parents presents a sobering insight into the aftermath of mother and baby homes.

Findings also indicate that issues with identity and belonging were a consequence of adoptive status. All participants spoke of not fitting in with peers or family members, feeling flawed and feeling disposable. Given how participants spoke about themselves, this finding would imply that self-esteem has been impacted by adoption. However, this diverges from meta-analytical findings of over 10,000 adoptees (Juffer and van IJzeendoorn, 2007), which found that adoptees, albeit adoptee children, had higher levels of self-esteem non-adoptees. Nevertheless, given the uniqueness of mother and baby homes and time spent in institutionalised care, it is difficult to directly compare mother and baby home survivors with adoptees.

Crucially, the present study highlights the importance of appropriate adoption placements and scrutiny of potential adopters. Adoptive parents' abuse and adverse parenting caused participants to engage in emotional internalising and help-seeking behaviour suppression. Still, research has shown that when adoptive or fostered children are provided with sensitive and well-organised placements, they might develop secure attachments with their adoptive parents and others (Steele et al., 2009; Smyke et al., 2010; Bakermans-Kranenburg et al., 2011). Therefore, appropriate adoption placements are imperative for adoptees' future development. 


\section{Strengths and limitations}

The current study has many strengths; it is the first study to utilise the AAI with a sample of mother and baby homes adoptees. To our knowledge, it is also the first study to use the AAI analysis in combination with thematic analysis; both analyses were performed by the same researcher who is AAI trained. Using this approach, we were able to present a more thorough understanding of attachment difficulties and trauma faced by our participants. Furthermore, we have not neglected sub-classification reporting in the results of the AAI analysis. Subclassification provides additional information regarding the participant's SOM, which is relevant both clinically and empirically. Finally, by interviewing participants directly, participants could represent themselves and their experiences in their own words giving rise to nuances in the data, which would have been missed using self-reports. These novel findings contribute to the broader discussion of trauma related to adoption and give practitioners a small-scale insight into this population.

One limitation of the study is that participants were recruited via a larger study of careexperienced and adopted adults. As mother and baby home survivors were not the focus of recruitment, many survivors who may have wanted to talk about their experiences may not have volunteered. Additionally, a greater sample size would have enabled us to test for a significant difference between our AAI findings and the ratios expected for the general population and compare these to that from clinical populations.

\section{Clinical implications}

The relationship between attachment and trauma is inextricable. Mothers such as those committed to mother and baby homes, with traumatic life histories and therefore probable insecure or unresolved attachment classification, increase the likelihood of their children having 
a similar classification (Main and Hesse, 1990; van IJzendoorn, 1995; Lyons-Ruth et al., 2005).

Practitioners should consider the use of attachment-based interventions to break this cycle of transgenerational trauma transmission, such as Minding the Baby (Sadler et a., 2013). As well as the likely transgenerational risks faced by this population, participants faced abuse and harsh parenting at the hands of their adoptive parents. The most recent update of the Berkeley Longitudinal Study showed that intervening trauma was strongly associated with a change in security from infant Strange Situation pattern to adult AAI classification (Main et al. 2005). Thus, there is a need for trauma-informed practice and appropriate intervention which address the additional traumatic experiences faced by patients with similar life histories.

Our results indicate that participants may be more susceptible to unresolved loss. This information may be particularly relevant to practitioners working with similar populations to inform therapeutic interventions to address loss. It is important that AAI analysis carried out in

clinical settings distinguish between those who are unresolved with regards to loss or trauma, as the two may bring about different interventions.

\section{Future research}

Research focusing on birth parent separation as a loss to adoptees is limited. A recent study (Barroso and Barbosa-Ducharne, 2019) concluded that most adoptees within their sample did not identify loss with their adoption experience. Although participants in the current study were unresolved with regards to loss. This finding cannot be attributed to loss of birth parents because separation from birth parents is not currently considered on the loss scale of the AAI. Unlike (Goldwyn and Hugh-Jones, 2011) no signs of marked disorientated speech during discussions of birth parents were observed. 
Nonetheless, there were eight references coded to separation as a loss during the qualitative analysis of the transcripts. Therefore, disorientated speech or further lapses associated with unresolved classification might have been observed if a special interest question regarding this separation had been added to the AAI protocol. Future research should seek to investigate adoptees perception of loss of birth parents. Further avenues for research include the impact of shame. It is likely that mothers committed to mother and baby homes felt and were made to feel shame for having children out of wedlock. It is known from previous research that feelings of shame are a significant predictor of PTSD symptoms (Andrews et al., 2000; Lee et al., 2001). In the current population there is potential to examine impact of intergenerational shame and trauma. Finally, to advance the field of attachment research and clinical understanding of attachment, more transparency is needed in future reporting of AAI classifications, including sub-classification and the specific cause of unresolved status.

\section{Conclusion}

This was the first study to analyse the attachment SOM and adoption experiences of the now-adult children adopted from mother and baby homes in the UK and Ireland. All participants had an insecure attachment SOM, the majority had an unresolved SOM, and preoccupied was the most prevalent forced three-way classification. Data indicates that the current study's mother and baby home adoptees may be more susceptible to trauma associated with loss. Additionally, this study highlights the importance of appropriate adoption placements and vetting of potential adopters. 


\section{References}

Ainsworth, M. D. S., Blehar, M. C., Waters, E., and Wall, S. 1978. Patterns of attachment: A psychological study of the strange situation. Lawrence Erlbaum.

Andrews, B., Brewin, C. R., Rose, S., \& Kirk, M. 2000. Predicting PTSD symptoms in victims of violent crime: the role of shame, anger, and childhood abuse. Journal of abnormal psychology, 109(1), 69-73. https://doi.org/10.1037//0021-843x.109.1.69.

Bakermans-Kranenburg, M. J., and Van IJzendoorn, M. H. 1993. A psychometric study of the Adult Attachment Interview: Reliability and discriminant validity. Developmental psychology, 29(5), 870. https://doi.org/10.1037/0012-1649.29.5.870.

Bakermans-Kranenburg, M. J., Steele, H., Zeanah, C. H., Muhamedrahimov, R. J., Vorria, P., Dobrova-Krol, N. A., Steele, M., van IJzendoorn, M. H., Juffer, F., and Gunnar, M. R. 2011. Attachment and Emotional Development in Institutional Care: Characteristics and Catch-Up. Monographs of the Society for Research in Child Development, 76(4), 62-91. 10.1111/j.1540-5834.2011.00628.x.

Barroso, R., and Barbosa-Ducharne, M. 2019. Adoption-related feelings, loss, and curiosity about origins in adopted adolescents. Clinical child psychology and psychiatry, 24(4), 876-891. https://doi.org/10.1177/1359104519858117.

Benjamin, T., Chang, D. F., and Steele, M. 2019. A qualitative study of "fa'a'amu” kinship care experiences in Tahiti. Adoption Quarterly, 22(3), 173-198.

https://doi.org/10.1080/10926755.2019.1625835

Braun, V., and Clarke, V. 2006. Using thematic analysis in psychology. Qualitative research in psychology, 3(2), 77-101.

Department of Children, Equality, Disability, Integration and Youth. 2021. Final Report of the 
Commission of Investigation into Mother and Baby Homes [Report]. Retrieved from https://assets.gov.ie/118565/107bab7e-45aa-4124-95fd-1460893dbb43.pdf

Dozier, M., Stoval, K. C., Albus, K. E., and Bates, B. 2001. Attachment for Infants in Foster Care: The Role of Caregiver State of Mind. Child Development, 72(5), 1467-1477. 10.1111/1467-8624.00360.

Duschinsky, R. 2020. Cornerstones of attachment research. Oxford University Press.

Edens, J. F., and Cavell, T. A. 1999. A Review and Reformulation of Adoptive Relationships from an Attachment Perspective. Adoption Quarterly, 3(2), 43-70. https://doi.org/10.1300/J145v03n02_04.

Ehrlich, K. B. 2019. Attachment and psychoneuroimmunology. Current opinion in psychology, 25, 96-100. https://doi.org/10.1016/j.copsyc.2018.03.012.

Ehrlich, K. B., Miller, G. E., Shalowitz, M., Story, R., Levine, C., Williams, D., ... and Chen, E. 2019. Secure base representations in children with asthma: Links with symptoms, family asthma management, and cytokine regulation. Child development, 90(6), e718-e728. https://doi.org/10.1111/cdev.13098.

Fearon, R. P., Bakermans-Kranenburg, M. J., Van IJzendoorn, M. H., Lapsley, A. M., and Roisman, G. I. 2010. The significance of insecure attachment and disorganisation in the development of children's externalising behavior: a meta-analytic study. Child development, 81(2), 435-456.

Feeney, J. A., Passmore, N. L., and Peterson, C. C. 2007. Adoption, attachment, and relationship concerns: A study of adult adoptees. Personal Relationships, 14(1), 129-147. https://doi.org/10.1111/j.1475-6811.2006.00145.x, 
Fonagy, P., Steele, M., Steele, H., Moran, G. S., and Higgitt, A. C. 1991. The capacity for understanding mental states: The reflective self in parent and child and its significance for security of attachment. Infant mental health journal, 12(3), 201-218.

https://doi.org/10.1002/1097-0355(199123)12:3<201::AID-IMHJ2280120307>3.0.CO;27.

George, C., Kaplan, N. and Main, M. 1985-1996. Adult Attachment Interview. Unpublished manuscript, Department of Psychology, University of California, Berkeley (third edition).

Goldwyn, R., and Hugh-Jones, S. 2011. Using the adult attachment interview to understand reactive attachment disorder: findings from a 10-case adolescent sample. Attachment and human development, 13(2), 169-191. 10.1080/14616734.2011.554006.

Juffer, F., and van IJzendoorn, M. H. 2007. Adoptees do not lack self-esteem: A meta-analysis of studies on self-esteem of transracial, international, and domestic adoptees. Psychological Bulletin, 133(6), 1067-1083. doi:10.1037/0033-2909.133.6.1067

Kennedy, M., Kreppner, J., Knights, N., Kumsta, R., Maughan, B., Golm, D., Hill, J., Rutter, M., Schlotz, W., and Sonuga-Barke, E. 2017. Adult disinhibited social engagement in adoptees exposed to extreme institutional deprivation: Examination of its clinical status and functional impact. British Journal of Psychiatry, 211(5), 289-295.

\section{https://doi.org/10.1192/bjp.bp.117.200618}

Main, M., Goldwyn, R., Hesse, E. 2003. Adult attachment scoring and classification systems. Unpublished manuscript.

Lee, D.A., Scragg, P. and Turner, S., 2001. The role of shame and guilt in traumatic events: A clinical model of shame - based and guilt - based PTSD. British journal of medical psychology, 74(4), pp.451-466. 
Lionetti, F., Pastore, M., and Barone, L. 2015. Attachment in institutionalised children: A review and meta-analysis. Child Abuse and Neglect, 42, 135-145.

\section{https://doi.org/10.1016/j.chiabu.2015.02.013}

Lyons-Ruth, K., Yellin, C., Melnick, S., and Atwood, G. 2005. Expanding the concept of unresolved mental states: Hostile/helpless states of mind on the Adult Attachment Interview are associated with disrupted mother-infant communication and infant disorganisation. Development and psychopathology, 17(1), 1. doi: $10.1017 / \mathrm{s} 0954579405050017$.

Main, M., Kaplan, N., and Cassidy, J. 1985. Security in infancy, childhood, and adulthood: A move to the level of representation. Monographs of the Society for Research in Child Development, 50(1-2), 66 -104. https://doi.org/10.2307/3333827.

Main, M., and Solomon, J. 1986. Discovery of an insecure-disorganised/disoriented attachment pattern. In T. B. Brazelton and M. W. Yogman (Eds.), Affective development in infancy (p. 95-124). Ablex Publishing.

Main, M., and Hesse, E. 1990. Parents' unresolved traumatic experiences are related to infant disorganised attachment status: Is frightened and/or frightening parental behavior the linking mechanism? In M. T. Greenberg, D. Cicchetti, and E. M. Cummings (Eds.), The John D. and Catherine T. MacArthur Foundation series on mental health and development. Attachment in the preschool years: Theory, research, and intervention (p. 161-182). University of Chicago Press.

Main, M., and Solomon, J. 1990. Procedures for identifying infants as disorganised/disoriented during the Ainsworth Strange Situation. Attachment in the preschool years: Theory, research, and intervention, 1, 121-160. 
Main, M. 1991. Metacognitive knowledge, metacognitive monitoring, and singular (coherent) vs. multiple (incoherent) model of attachment: Findings and directions for future research. In C. M. Parkes, J. Stevenson-Hinde, and P. Marris (Eds.), Attachment across the life cycle (p. 127-159). Tavistock/Routledge.

Main, M. 2000. The organised categories of infant, child, and adult attachment: Flexible vs. inflexible attention under attachment-related stress. Journal of the American Psychoanalytic Association, 48(4), 1055-1096. 10.1177/00030651000480041801.

Main, M., Hesse, E., and Kaplan, N. 2005. Predictability of Attachment Behavior and Representational Processes at 1, 6, and 19 Years of Age: The Berkeley Longitudinal Study.

McCormick, L., O’Connell, S., Dee, O., and Privilege, J. 2021. Mother and Baby Homes and Magdalene Laundries in Northern Ireland, 1922-1990. Research Report on Mother and Baby Homes and Magdalene Laundries in Northern Ireland $\mid$ Department of Health (health-ni.gov.uk)

McMahon, C. A., Barnett, B., Kowalenko, N. M., and Tennant, C. C. 2006. Maternal attachment state of mind moderates the impact of postnatal depression on infant attachment. Journal of Child Psychology and Psychiatry, 47(7), 660-669. https://doi.org/10.1111/j.1469$\underline{7610.2005 .01547 . x}$

Dagan, O., Asok, A., Steele, H., Steele, M., and Bernard, K. 2018. Attachment security moderates the link between adverse childhood experiences and cellular aging. Development and psychopathology, 30(4), 1211-1223. https://doi.org/10.1017/S0954579417001705. 
Sadler, L. S., Slade, A., Close, N., Webb, D. L., Simpson, T., Fennie, K., and Mayes, L. C. 2013. Minding the Baby: Enhancing Reflectiveness to Improve Early Health and Relationship Outcomes in an Interdisciplinary Home-Visiting Program. Infant mental health journal, 34(5), 391-405. 10.1002/imhj.21406.

Smyke, A. T., Zeanah, C. H., Fox, N. A., Nelson, C. A., and Guthrie, D. 2010. Placement in foster care enhances quality of attachment among young institutionalised children. Child development, 81(1), 212-223. https://doi.org/10.1111/j.1467-8624.2009.01390.x.

Steele, H., Steele, M., and Fonagy, P. 1996. Associations among attachment classifications of mothers, fathers, and their infants. Child development, 67(2), 541-555.

Steele, M., Hodges, J., Kaniuk, J., Hhillman, S., and Henderson, K. 2003. Attachment representations and adoption: Associations between maternal states of mind and emotion narratives in previously maltreated children. Journal of Child Psychotherapy, 29(2), 187205. https://doi.org/10.1080/0075417031000138442.

Steele, M., Hodges, J., Kaniuk, J., and Steele, H. 2009. Mental representation and change: Developing attachment relationships in an adoption context. Psychoanalytic Inquiry, 30(1), 25-40. https://doi.org/10.1080/07351690903200135.

van den Dries, L., Juffer, F., van IJzendoorn, M. H., and Bakermans-Kranenburg, M. J. 2009. Fostering security? A meta-analysis of attachment in adopted children. Children and Youth Services Review, 31(3), 410-421. https://doi.org/10.1080/07351690903200135.

Van IJzendoorn, M. H. 1992. Intergenerational transmission of parenting: A review of studies in nonclinical populations. Developmental Review, 12(1), 76-99. https://doi.org/10.1016/0273-2297(92)90004-L.

Van Ijzendoorn, M. H. 1995. Adult attachment representations, parental responsiveness, and 
infant attachment: a meta-analysis on the predictive validity of the Adult Attachment Interview. Psychological bulletin, 117(3), 387. https://doi.org/10.1037/00332909.117.3.387.

van Ijzendoorn, M. H., and Bakermans-Kranenburg, M. J. 1996. Attachment representations in mothers, fathers, adolescents, and clinical groups: A meta-analytic search for normative data. Journal of consulting and clinical psychology, 64(1), 8. 10.1037//0022-006x.64.1.8. van Ijzendoorn, M. H., and Juffer, F. 2006. The Emanuel Miller Memorial Lecture 2006: Adoption as intervention. Meta-analytic evidence for massive catch-up and plasticity in physical, socio-emotional, and cognitive development. Journal of child psychology and psychiatry, 47(12), 1228-1245. 10.1111/j.1469-7610.2006.01675.

van Ijzendoorn, M. H., and Bakermans-Kranenburg, M. J. 2008. The distribution of adult attachment representations in clinical groups: A meta-analytic search for patterns of attachment in 105 AAI studies. In H. Steele and M. Steele (Eds.), Clinical applications of the Adult Attachment Interview (p. 69-96). The Guilford Press. 